\title{
PENGARUH KOMITMEN PROFESI DAN SELF EFFICACY TERHADAP NIAT UNTUK MELAKUKAN WHISTLE BLOWING
}

\author{
Tria Heni Hidayati \\ Prodi Akuntansi Universitas Negeri Yogyakarta \\ tria.henny@gmail.com \\ Pembimbing: \\ Adeng Pustikaningsih \\ Staf Pengajar Jurusan P. Akuntansi Universitas Negeri Yogyakarta
}

\begin{abstract}
Abstrak : Pengaruh Komitmen Profesi Dan Self Efficacy Terhadap Niat Untuk Melakukan Whistle Blowing. Penelitian ini untuk mengetahui: (1) Pengaruh komitmen profesi terhadap niat untuk melakukan whistle blowing, (2) Pengaruh self efficacy terhadap niat untuk melakukan whistle blowing, (3) Pengaruh komitmen profesi dan self efficacy terhadap niat untuk melakukan whistle blowing. Populasi adalah bagian keuangan rumah sakit di Kabupaten Purworejo berjumlah 76 orang. Teknik pengumpulan data menggunakan kuesioner. Teknik sampling menggunakan sampel jenuh. Jumlah sampel terkumpul 51 orang. Hasil penelitian menunjukkan (1) Komitmen profesi berpengaruh positif terhadap niat untuk melakukan whistle blowing ditunjukkan nilai konstanta

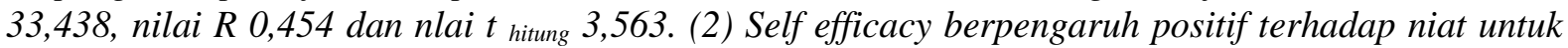
melakukan whistle blowing ditunjukkan nilai konstanta 30,214, nilai $R$ 0,319 dan nilai $t$ hitung 2,356. (3) Komitmen profesi dan self efficacy secara bersama-sama berpengaruh positif terhadap niat untuk melakukan whistle blowing ditunjukkan nilai $R$ 0,541 dan nilai $F$ hitung 9,942.
\end{abstract}

Kata kunci : Komitmen Profesi, Self Efficacy, Whistle Blowing

\begin{abstract}
The Influence Of Professional Commitment And Self Efficacy On The Intention To Do Whistle Blowing. This study to determine: (1) The influence of professional commitment on the intention to do whistle blowing. (2) The influence of self-efficacy on the intention to do whistle blowing. (3) The influence of professional commitment and self-efficacy on the intention to do whistle blowing. The population is part of the hospital's financial at Purworejo Regency amount 76 people. Data collection technique using questionnaire. Sampling technique using saturated sample. The number of sample collected 51 people. Results showed (1) Professional commitment has positive influence on the intention to do whistle blowing, the value of constant is 33,438, the value of $r$ is 0,454 , and the value of $t$ is 3,563. (2) Self-efficacy has positive influence on the intention to do whistle blowing, the value of constant is 30,214, the value of $r$ is 0,319, and the value of $t$ is 2,356. (3) Professional commitment and self-efficacy simultaneously has positive influence on the intention to do whistle blowing, the value of $r$ is 0,541 and the value of $F$ is 9,942 .
\end{abstract}

Keywords: Professional Commitment, Self Efficacy, Whistle Blowing

\section{PENDAHULUAN}

Maraknya kasus pelanggaran akuntansi di dalam dan di luar negeri mencerminkan ketidakprofesionalan dan pelanggaran etis akuntan. Profesi akuntansi sebagai profesi penyedia informasi sudah seharusnya menyediakan informasi yang terpercaya. Kegagalan dalam menyediakan informasi 


\section{JURNAL NOMINAL / VOLUME V NOMOR 1 / TAHUN 2016}

yang terpercaya dapat mengakibatkan kerugian bagi para pengguna laporan keuangan. Kerugian tersebut dikarenakan para pengguna laporan keuangan mendasarkan keputusannya pada informasi yang disajikan oleh profesi akuntansi, sehingga informasi yang salah dapat berujung pada keputusan yang salah pula.

Kegagalan mencegah dan mendeteksi kecurangan mempunyai konsekuensi serius bagi organisasi. Di AS, diperkirakan biayabiaya keuangan yang dihubungkan dengan kecurangan karyawan sekitar US\$50 milyar tiap tahun (Anayanti Rahmawati, 2010: 5). Suatu survei yang terbaru di UK menunjukkan bahwa biaya kecurangan karyawan kepada perusahaan yang tercatat sejumlah £ 2 milyar dalam satu tahun (Management Issues News). Dalam tahun 2004, di Australia dan Selandia Baru, KPMG meneliti sebanyak 491 bisnis dari berbagai macam industri yang menunjukkan bahwa 27.657 peristiwa dari kecurangan di dalam satu tahun, mulai April 2002 sampai dengan Maret 2004 dengan total kerugian sejumlah A \$4567 juta (KPMG Forensic).

Di Indonesia kecurangan atau pelanggaran etika juga bisa terjadi di mana saja, baik itu industri perdagangan maupun jasa seperti perhotelan dan rumah sakit (Dwi Ambarini, 2013: 2). Banyak hal yang berhubungan dengan pelanggaran etika bisnis yang sering dilakukan oleh para pebisnis yang tidak bertanggung jawab di Indonesia. Praktik bisnis yang terjadi selama ini dinilai masih cenderung mengabaikan etika, rasa keadilan, dan diwarnai praktikpraktik tidak terpuji atau moral hazard. Pelaku kecurangan dalam organisasi bisa dalam bentuk korupsi, penyalahgunaan aset, maupun pelaporan keuangan yang curang. Kecurangan tersebut dilakukan dalam kaitannya dengan jabatan seseorang yang dengan sengaja salah menggunakan maupun salah mengaplikasikan sumberdaya atau aset perusahaan (ACFE).

Di Indonesia, sudah terdeteksi berbagai praktek yang menjurus korupsi di level mikro pelayanan klinis dan sistem manajemen rumah sakit, antara lain : dokumen asuransi yang tidak beres, tagihan perawatan yang tidak sah; pembelian obat dan bahan habis pakai yang fiktif; penjualan bahan dan obat yang tidak sesuai aturan dan cenderung merugikan masyarakat; dokter tidak aktif menangani pasien (mewakilkan ke dokter lain atau residen) namun menerima jasa, kolusi dengan pabrik/distributor obat dan alat kesehatan yang merugikan pasien. Akibat dari tindak kecurangan dapat berupa kerusakan fisik, kemacetan pembangunan fisik, nama baik dan citra, termasuk keluarganya, karir berhenti, mutu pelayanan rumah sakit menurun, dan sebagainya. (Laksono Trisnantoro, 2013). 


\section{JURNAL NOMINAL / VOLUME V NOMOR 1 / TAHUN 2016}

Kerugian dari kecurangan akuntansi adalah menurunnya akuntabilitas manajemen dan membuat para pemegang saham meningkatkan biaya monitoring terhadap manajemen. Pada umumnya kecurangan akuntansi berkaitan dengan korupsi. Dalam korupsi tindakan yang lazim dilakukan diantaranya adalah memanipulasi pencatatan, penghilangan dokumen dan mark-up. Hal tersebut merupakan tindakan yang merugikan keuangan organisasi.

Oleh karena itu, diperlukan adanya pengendalian intern untuk mengarahkan, mengawasi, dan mengukur sumber daya suatu organisasi. Pengendalian ini berperan penting untuk mencegah dan mendeteksi kecurangan serta melindungi sumber daya organisasi, baik yang berwujud maupun tidak. Salah satu bentuk pengendalian intern untuk mencegah pelanggaran akuntansi sehingga dapat mengembalikan kepercayaan masyarakat adalah dengan melakukan whistle blowing. Whistle blowing adalah pelaporan yang dilakukan oleh anggota organisasi (aktif maupun non aktif) mengenai pelanggaran, tindakan ilegal, atau tidak bermoral kepada pihak di dalam maupun di luar organisasi (Theodorus M. Tuanakotta, 2010).

Menjadi whistle blower merupakan tindakan yang berisiko karena terdapat ancaman fisik dan psikis baik secara langsung maupun tidak langsung dari pihak tertentu yang mengakibatkan whistle blower merasa takut dan dipaksa untuk melakukan atau tidak melakukan sesuatu yang berkenaan dengan kesaksiannya dalam suatu kasus. Hal ini merupakan salah satu penyebab rendahnya keberanian untuk mengungkap kecurangan (Theodorus $\mathrm{M}$. Tuanakotta, 2010: 614). Rendahnya keberanian mengungkap kecurangankecurangan yang ada dalam sebuah perusahaan menimbulkan pertanyaan tentang faktor-faktor yang mempengaruhi niat individu untuk melakukan whistle blowing.

Komitmen profesi dalam beberapa penelitian ditemukan memiliki peran dalam niat untuk melakukan whistleblowing. Elias Rafik Z (2008) menyatakan bahwa level komitmen profesi mempengaruhi level landasan etis. Lebih lanjut, Kaplan dan Whitecotton (2001) dalam Risti Merdikawati (2012: 28) menemukan bahwa terdapat hubungan positif antara komitmen profesi dan niat auditor dalam melakukan whistleblowing. Hasil penelitian tersebut mengindikasikan bahwa akuntan yang lebih berkomitmen terhadap profesinya lebih memiliki kecenderungan untuk melaporkan pelanggaran.

Menjadi whistle blower merupakan tindakan yang berisiko karena terdapat ancaman fisik dan psikis baik secara langsung maupun tidak langsung dari pihak 


\section{JURNAL NOMINAL / VOLUME V NOMOR 1 / TAHUN 2016}

tertentu yang mengakibatkan whistle blower merasa takut dan dipaksa untuk melakukan atau tidak melakukan sesuatu yang berkenaan dengan kesaksiannya dalam suatu kasus. Individu dengan self efficacy yang tinggi akan cenderung lebih berani untuk mengungkapkan kecurangan yang terjadi di lingkungan organisasinya karena dia mempunyai keyakinan terhadap kemampuan mereka (Macnab Brent R \& Worthley Reginald, 2008: 3). Hal ini didukung oleh pendapat Ratno Purnomo dan Sri Lestari (2010: 147) bahwa self efficacy memainkan peran yang penting dalam perilaku etis dalam sebuah organisasi.

Meskipun di Indonesia penelitian mengenai whistle blowing sudah pernah dilakukan, namun penelitian sebelumnya telah meneliti faktor-faktor penentu seseorang melakukan whistle blowing di kalangan akuntan perusahaan, auditor, dan mahasiswa. Sedangkan di kalangan akuntan rumah sakit masih jarang dilakukan.

Penelitian ini akan membuktikan faktor-faktor yang mempengaruhi antara intensi dalam melakukan whistle blowing berdasarkan theory of planned behavior (TPB).

\section{METODE PENELITIAN}

\section{Jenis Penelitian}

Metode penelitian yang digunakan dalam mencari dan mengolah data adalah penelitian kuantitatif. Jenis penelitian ini adalah penelitian asosiatif dimana penelitian untuk mengetahui hubungan sebab-akibat antara variabel bebas (variabel independen) dengan variabel terikat (variabel dependen).

\section{Waktu dan Tempat Penelitian}

Penelitian dilakukan di bagian keuangan pada setiap rumah sakit di Kabupaten Purworejo yaitu RSUD Saras Husada, RSIA Kasih Ibu, RSIA 'Aisyiyah, dan RSIA Permata pada bulan April 2014.

\section{Populasi}

Populasi pada penelitian ini adalah bagian keuangan pada setiap rumah sakit di Kabupaten Purworejo yang berjumlah 76 orang.

\section{Prosedur}

Peneliti membagikan kuesioner langsung kepada responden untuk diisi kemudian dikembalikan kepada peneliti.

\section{Data, Instrumen, dan Teknik \\ Pengumpulan}

\section{Data}

Data dalam penelitian ini merupakan data primer yang dikumpulkan secara langsung oleh peneliti menggunakan daftar pernyataan dengan skor skala sikap model likert yang disusun berdasarkan instrumen penelitian. Instrumen dari variabel whistle blowing menurut Hwang and Staley (2013) adalah faktor yang mendorong untuk melakukan whistle bowing antara lain kedilan sosial dan etika profesi, moral, 


\section{JURNAL NOMINAL / VOLUME V NOMOR 1 / TAHUN 2016}

imbalan uang, dorongan rekan, hukum dan kebijakan, dampak dalam organisasi dan dampak ke masyarakat. Sedangkan faktor yang menghambat untuk melakukan whistle blowing antara lain kekuatan sistem kontrol internal, perhatian media, pembalasan, dan keyakinan yang rendah. Instrumen dari variabel komitmen profesi menurut Allen dan Meyer (1999) adalah komitmen afektif, komitmen normatif, dan komitmen berkelanjutan. Instrumen dari variabel self efficacy menurut Bandura (1986) adalah dimensi magnitude, strength, dan generality.

\section{Teknik Analisis Data}

Teknik analisis data dalam penelitian ini menggunakan program SPPS 17.0 for Windows.

\section{Uji Instrumen Data}

Sebuah instrumen harus diuji terlebih dahulu sebelum digunakan untuk mengukur variabel. Instrumen dapat digunakan jika memenuhi syarat yaitu valid dan reliabel. Dikatakan valid berarti instrumen tersebut dapat digunakan untuk mengukur apa yang akan diukur (Sugiyono, 2010). Instrumen dikatakan reliabel jika jawaban dari responden konsisten dan stabil. (Imam Ghozali, 2006: 45)

\section{1) Analisis Statistik Deskriptif}

Analisis ini digunakan untuk mendeskripsikan variabel bebas dan variabel terikat. Digunakan tabel distribusi untuk menyajikan data yang telah diolah dari responden.

\section{2) Uji Asumsi Klasik}

Oleh karena penelitian ini menggunakan alat analisis regresi berganda, maka perlu dilakukan uji prasyarat analisis terlebih dahulu.

a) Uji Normalitas, bertujuan untuk menguji apakah dalam model regresi variabel bebas dan terikat berdistribusi normal (Imam Ghozali, 2006: 147). Digunakan teknik Kolmogorov-Smirnov dalam uji ini. Dikatakan normal, apabila nilai taraf signifikansinya lebih dari 0,05.

b) Uji Multikolinieritas, bertujuan untuk mendeteksi gejala korelasi antar variabel independen. Model regresi yang baik tidak terjadi gejala korelasi. Uji dilakukan dengan melihat nilai VIF dan nilai tolerance. Apabila nilai VIF > 10 dan nilai tolerance $<0,10$, maka tidak terjadi gejala multikolinieritas. (Imam Ghozali, 2006)

c) Uji Heteroskedastisitas, bertujuan untuk menguji apakah dalam model regresi terjadi ketidaksamaan varian dari residual satu pengamatan ke pengamatan yang lain, yang disebut heteroskedastisitas. Model yang baik adalah homokedastisitas. Uji ini menggunakan teknik Glesjer yang apabila nilai signifikansi masing-masing variabel lebih dari 0,05 maka tidak terjadi heteroskedastisitas. (Imam Ghozali: 2006) 


\section{JURNAL NOMINAL / VOLUME V NOMOR 1 / TAHUN 2016}

d) Uji Linearitas, bertujuan untuk mengetahui apakah variabel bebas dan terikat memiliki hubungan linear atau tidak. Uji ini dilakukan dengan melihat nilai Deviation from Linearity. Dua variabel dikatakan linear apabila nilai signifikansinya lebih dari 0,05 .

\section{3) Uji Hipotesis}

a) Analisis Regresi Linear Sederhana

Digunakan untuk menguji hipotesis 1 dan 2. Dalam analisis regresi sederhana, langkah yang ditempuh adalah membuat garis regresi linear sederhana dan membandingkan $t_{\text {tabel }}$ dengan $t_{\text {hitung. Apabila }}$ $t_{\text {hitung }}$ lebih besar dari $t_{\text {tabel}}$, maka hipotesis diterima.

b) Analisis Regresi Linear Berganda

Digunakan untuk menguji hipotesis 3. Langkah yang ditempuh adalah: mencari persamaan garis prediktor, mencari koefisien determinasi, membandingkan $F_{\text {hitung dengan }} \mathrm{F}_{\text {tabel }}$ Hipotesis diterima apabila nilai $F_{\text {hitung }}$ lebih besar dari $F_{\text {tabel. }}$

\section{HASIL}

PENELITIAN

DAN

PEMBAHASAN

\section{Statistik Deskriptif}

a. Variabel Niat Whistle Blowing

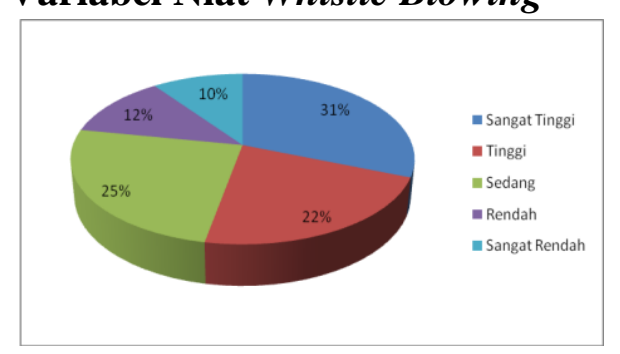

Gambar 1. Pie Chart Whistle Blowing

Dari data diatas dapat dilihat bahwa niat whistle blowing profesi pada bagian keuangan rumah sakit di Kabupaten Purworejo adalah yang ditunjukkan dengan persentase $31 \%$.

\section{b. Variabel Komitmen Profesi}

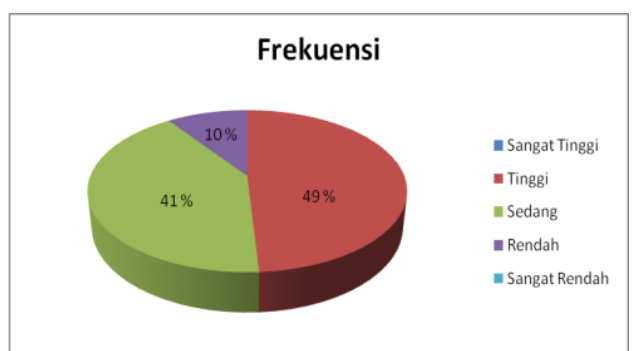

Gambar 2. Pie Chart Komitmen

Profesi

Dari data diatas dapat dilihat bahwa komitmen profesi pada bagian keuangan rumah sakit di Kabupaten Purworejo adalah tinggi yang ditunjukkan dengan persentase $49 \%$.

\section{c. Variabel Self Efficacy}

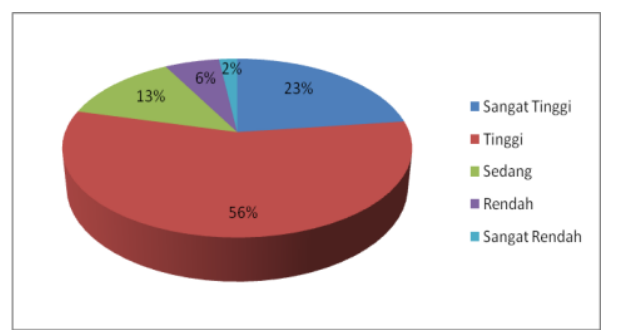

Gambar 3. Pie Chart Self Efficacy

Dari data diatas dapat dilihat bahwa self efficacy pada bagian keuangan rumah sakit di Kabupaten Purworejo adalah tinggi yang ditunjukkan dengan persentase $56 \%$.

\section{Hasil Uji Asumsi Klasik}

a. Uji Normalitas 


\section{JURNAL NOMINAL / VOLUME V NOMOR 1 / TAHUN 2016}

Berdasarkan hasil uji normalitas, diketahui nilai Asymp. Sig. > 0,05 maka dapat disimpulkan bahwa data yang diperoleh berdistribusi normal.

b. Uji Multikolinearitas

Tabel 1. Hasil Uji Multikolinearitas

\begin{tabular}{llll}
\hline Variabel & Tolerance & VIF & \multicolumn{2}{l}{ Keterangan } \\
\hline $\mathbf{X 1}$ & 0,997 & 1,003 & $\begin{array}{l}\text { Tidak } \\
\text { multikolinearitas }\end{array}$ \\
\hline $\mathbf{X 2}$ & 0,997 & 1,003 & $\begin{array}{l}\text { Tidak } \\
\text { terjadi } \\
\text { multikolinearitas }\end{array}$ \\
\hline
\end{tabular}

Sumber: data primer diolah, 2014

Dari tabel diatas diketahui bahwa semua data memiliki nilai tolerance $>0,10$ dan nilai $\mathrm{VIF}<10$, maka dapat disimpulkan bahwa tidak terjadi gejala multikolinieritas.

c. Uji Heteroskedastisitas

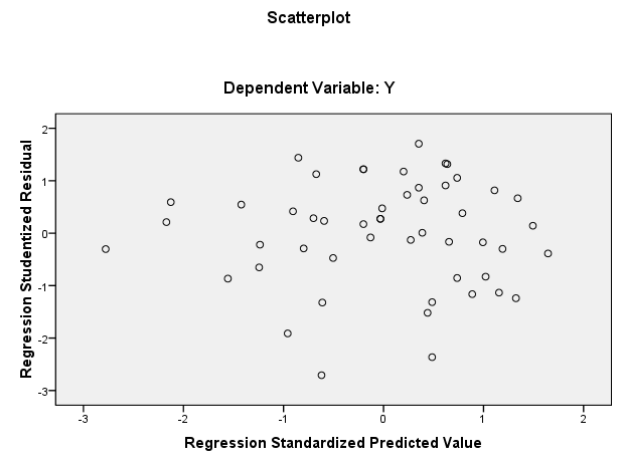

Sumber: data primer diolah, 2014

Gambar 4. Grafik Scatterplot

Dari gambar diatas dapat dilihat bahwa titik-titik menyebar secara acak, baik di bagian atas angka nol atau di bagian bawah angka nol dari sumbu vertikal atau sumbu Y. Dengan demikian dapat disimpulkan bahwa tidak terjadi heteroskedastisitas. d. Uji Linearitas

Tabel 2. Hasil Uji Linearitas

\begin{tabular}{lcrl}
\hline Variabel & F Hitung & F Tabel & Keterangan \\
\hline X1-Y & 1.017 & 4.0384 & Linear \\
\hline X2-Y & 1.590 & 4.0384 & Linear
\end{tabular}

Sumber: data primer diolah, 2014

Berdasarkan hasil uji linearitas di atas menunjukkan bahwanilai $F$ hitungvaraibel bebas lebih kecildari $F$ tabel.Dengan demikian dapat disimpulkan bahwa hubungan antara variabel $\mathrm{X}$ dan variabel $\mathrm{Y}$ adalah linear.

\section{Hasil Uji Hipotesis}

a. Analisis Regresi Linear Sederhana

$\mathrm{H}_{1}$ : Komitmen profesi berpengaruh positif terhadap niat untuk melakukan whistle blowing.

Tabel 3. Hasil Analisis $\mathrm{X}_{1}$ terhadap Y

\begin{tabular}{lccc}
\hline Variabel & $\begin{array}{c}\text { Koefisien } \\
\text { Regresi }\end{array}$ & thitung & Sig \\
\hline Konstanta & 33,438 & 6,796 & 0,000 \\
\hline $\begin{array}{l}\text { Komitmen } \\
\text { Profesi }\end{array}$ & 0,422 & 3,563 & 0,001 \\
\hline r: 0,454 & & & \\
\hline R Square : $\mathbf{0 , 2 0 6}$ & & \\
\hline
\end{tabular}

Sumber: data primer diolah, 2014

Berdasarkan tabel diatas, persamaannya adalah:

$$
\mathrm{Y}=33,438+0,422 \mathrm{X}
$$

Berdasarkan hasil perhitungan regresi linear sederhana yang ditunjukkan tabel di atas dapat diketahui nilai konstanta sebesar 33.438 menunjukkan bahwa besarnya niat untuk melakukan whistle blowing (Y) 


\section{JURNAL NOMINAL / VOLUME V NOMOR 1 / TAHUN 2016}

sebesar 33,438 tanpa dipengaruhi oleh komitmen profesi $\left(\mathrm{X}_{1}=0\right)$. Jika komitmen profesi meningkat sebesar 1 satuan maka niat untuk melakukan whistle blowing (Y) akan meningkat sebesar 0,422. Hal ini berarti komitmen profesi $\left(\mathrm{X}_{1}\right)$ berpengaruh positif terhadap niat untuk melakukan whistle blowing (Y).

Nilai koefisien korelasi (r) bernilai positif sebesar 0,454 dan $R$ square $\left(R^{2}\right)$ yang diperoleh sebesar 0,206 (20,6\%). Hal ini berarti variabel komitmen profesi mempengaruhi variabel niat whistle blowing sebesar $\mathrm{R}^{2}$ atau sebesar 20,6\%, sedangkan sisanya sebesar $79,4 \%$ dipengaruhi oleh variabel lain diluar penelitian ini.

Nilai signifikansi sebesar 0,001 dan nilai $t_{\text {hitung }}$ sebesar 3,563. Karena nilai signifikansi lebih kecil dari $0,05(0,001<$ $0,05)$, nilai $t_{\text {hitung }}$ lebih besar dari $t_{\text {tabel }} 3,563$ $(3,563>2,007)$ dan koefisien korelasi (r) memiliki arah positif sebesar 0,454 maka hipotesis pertama yang menyatakan "Komitmen profesi berpengaruh positif terhadap niat untuk melakukan whistle blowing" diterima.

$\mathrm{H}_{2}$ : Self Efficacy berpengaruh positif terhadap niat untuk melakukan whistle blowing.

Tabel 4. Hasil Analisis $\mathrm{X}_{2}$ terhadap Y

\begin{tabular}{cccc}
\hline Variabel & $\begin{array}{c}\text { Koefisien } \\
\text { Regresi }\end{array}$ & thitung & Sig \\
\hline Konstanta & 30,214 & 3,448 & 0,001 \\
\hline
\end{tabular}

\begin{tabular}{llll}
\hline $\begin{array}{l}\text { Self } \\
\text { Efficacy }\end{array}$ & 0,498 & 2,356 & 0,023 \\
\hline r : 0,319 & & & \\
\hline R Square : $\mathbf{0 , 1 0 2}$ & & \\
\hline
\end{tabular}

Sumber: data primer diolah, 2014

Berdasarkan tabel diatas, persamaannya adalah:

$$
Y=30,214+0,498 X
$$

Berdasarkan hasil perhitungan regresi linear sederhana yang ditunjukkan pada tabel di atas dapat diketahui bahwa nilai konstanta sebesar 30.214 menunjukkan besarnya niat untuk melakukan whistle blowing (Y) sebesar 30.214 tanpa dipengaruhi oleh self efficacy $\left(\mathrm{X}_{2}=0\right)$. Jika self efficacy meningkat sebesar 1 satuan maka niat untuk melakukan whistle blowing (Y) akan meningkat sebesar 0.498. Hal ini berarti self efficacy $\left(\mathrm{X}_{2}\right)$ berpengaruh positif terhadap niat untuk whistle blowing $(\mathrm{Y})$.

Nilai koefisien korelasi (r) bernilai positif sebesar 0,319 dan $R$ square $\left(R^{2}\right)$ yang diperoleh sebesar 0,102 (10,2\%). Hal ini berarti variabel self efficacy mempengaruhi variabel niat whistle blowing sebesar $\mathrm{R}^{2}$ atau sebesar 10,2\%, sedangkan sisanya sebesar $89,8 \%$ dipengaruhi oleh variabel lain diluar penelitian ini.

Nilai signifikansi sebesar 0,023 dan nilai $t_{\text {hitung }}$ sebesar 2,356. Karena nilai signifikansi lebih kecil dari 0,05 $(0,023<0,05)$, nilai $t_{\text {hitung }}$ lebih besar dari $t_{\text {tabel }} 2,356 \quad(2,356>2,007)$ dan koefisien 


\section{JURNAL NOMINAL / VOLUME V NOMOR 1 / TAHUN 2016}

korelasi (r) memiliki arah positif sebesar 0,319 maka hipotesis kedua yang menyatakan "Self efficacy berpengaruh positif terhadap niat untuk melakukan whistle blowing" diterima.

b. Analisis Regresi Linear Berganda

$\mathrm{H}_{3}$ : Komitmen profesi dan self efficacy secara bersama-sama berpengaruh positif terhadap niat untuk melakukan whistle blowing.

Tabel 5. Analisis Regresi Linear Berganda Variabel

\section{Koefisien}

\section{Regresi}

\begin{tabular}{ll}
\hline Konstanta & 14,977 \\
\hline Komitmen profesi & 0,408 \\
\hline Self Efficacy & 0,462 \\
\hline $\mathbf{R}$ & 0,541 \\
\hline Adjusted $\boldsymbol{R}$ Square & 0,263 \\
\hline F $_{\text {hitung }}$ & 9,942 \\
\hline Ftabel & 3,1907 \\
\hline Sig F & 0,000 \\
\hline
\end{tabular}

Berdasarkan tabel diatas, persamaannya adalah:

$\mathrm{Y}=14,977+0,408 \mathrm{X}_{1}+0,462 \mathrm{X}_{2}$

Nilai koefisien $\mathrm{X}_{1}$ sebesar 0,408 yang berarti komitmen profesi meningkat 1 poin maka niat untuk melakukan whistle blowing akan naik sebesar 0,408 satuan dengan asumsi $\mathrm{X}_{2}$ tetap. Nilai koefisien $\mathrm{X}_{2}$ sebesar 0,462 yang berarti bahwa self efficacy meningkat 1 poin maka niat untuk melakukan whistle blowing akan naik sebesar 0,462 satuan dengan asumsi $X_{1}$ tetap.Hal ini juga dapat dilihat dari nilai korelasi regresi (R) yang bernilai positif antara komitmen profesi dan self efficacy terhadap niat untuk melakukan whistle blowing sebesar 0,541.

Nilai koefisien korelasi (r) bernilai positif sebesar 0,541 dan adjusted $\mathrm{R}$ square $\left(\mathrm{R}^{2}\right)$ yang diperoleh sebesar 0,263 (26,3\%). Hal ini berarti variabel komitmen profesi dan self efficacy secara bersama-sama mempengaruhi variabel niat whistle blowing sebesar $\mathrm{R}^{2}$ atau sebesar $26,3 \%$, sedangkan sisanya sebesar $73,7 \%$ dipengaruhi oleh variabel lain diluar penelitian ini.

Nilai signifikansi sebesar 0,000 dan nilai $F_{\text {hitung }}$ sebesar 9,942. Karena nilai signifikansi lebih kecil dari 0,05 (0,000< 0,05) dan nilai $F_{\text {hitung }}$ lebih besar dari $F_{\text {tabel }}$ 3,1907 dan koefisien korelasi (r) memiliki arah positif sebesar 0,541 maka hipotesis ke tiga yang menyatakan "Komitmen profesi dan self efficacy secara bersama-sama berpengaruh positif terhadap niat whistle blowing" diterima.

\section{KESIMPULAN DAN SARAN KESIMPULAN}

a. Terdapat pengaruh positif komitmen profesi terhadap niat whistle blowing. Hal ini dibuktikan dengan dengan nilai thitung 3,563 lebih besar dari $t_{\text {tabel }} 2,007$ $(3,563>2,007)$ dan nilai signifikansi yang diperoleh $0,001(0,001<0,05)$. Nilai koefisien regresi sebesar 0,422 yang memiliki arah positif yang berarti semakin 


\section{JURNAL NOMINAL / VOLUME V NOMOR 1 / TAHUN 2016}

tinggi komitmen profesi maka niat untuk melakukan whistle blowing juga semakin tinggi. Nilai koefisien korelasi sebesar 0,454 dan koefisien determinasi sebesar 0,206 $(20,6 \%)$ yang berarti komitmen profesi berpengaruh secara positif terhadap niat whistle blowing sebesar 20,6\%.

b. Terdapat pengaruh positif self efficacy terhadap niat whistle blowing. Hal ini dibuktikan dengan nilai thitung 2,356 lebih besar dari tabel $2,007(2,356>2,007)$ dan nilai signifikansi yang diperoleh 0,023 $(0,023<0,05)$. Nilai koefisien regresi sebesar 0,498 yang memiliki arah positif yang berarti semakin tinggi self efficacy maka niat whistle blowing juga semakin tinggi. Nilai koefisien korelasi sebesar 0,319 dan koefisien determinasi sebesar 0,102 (10,2\%) yang berarti self efficacy berpengaruh secara positif terhadap niat whistle blowing sebesar $10,2 \%$.

c. Terdapat pengaruh positif komitmen profesi dan self efficacy terhadap niat whistle blowing. Hal ini dibuktikan dengan nilai Fhitung 9,942 lebih besar dari Ftabel 3,1907 $(9,942>3,1907)$ dan nilai signifikansi yang diperoleh $0,000(0,000<0,05)$ maka dapat disimpulkan bahwa komitmen profesi dan self efficacy secara bersama-sama berpengaruh positif terhadap niat whistle blowing. Nilai koefisien korelasi sebesar 0,919 dan nilai adjusted $R$ square sebesar $0,541(54,1 \%)$ yang berarti komitmen profesi dan self efficacy secara bersamasama berpengaruh terhadap niat whistle blowing dan sisanya sebesar $45,9 \%$.

\section{SARAN}

1. Dalam pengumpulan data, penelitian ini menggunakan kuesioner. Oleh karena itu data yang dikumpulkan hanya menggambarkan pendapat responden terhadap niat untuk melakukan whistle blowing dan peneliti tidak bisa mengontrol jawaban responden yang tidak menunjukkan keadaan yang sesungguhnya. Maka penelitian selanjutnya diharapkan dapat menggunakan metode penelitian yang berbeda, seperti metode wawancara langsung kepada responden agar mencerminkan jawaban atas kondisi yang sebenarnya.

2. Penelitian ini perlu diuji lagi dengan melibatkan responden yang berbeda, memperbesar jumlah sampel penelitian, dan tidak hanya mencakup wilayah Kabupaten Purworejo untuk melihat apakah terdapat perbedaan hasil penelitian.

3. Penelitian ini hanya menggunakan variabel komitmen profesi dan self efficacy yang merupakan faktor internal sebagai variabel bebas yang mempengaruhi timbulnya niat untuk melakukan whistle blowing. Penelitian 
selanjutnya dapat menambah faktor eksternal seperti keadilan sosial, etika profesi, kompensasi, dan hukum sebagai variabel bebas yang dapat mempengaruhi niat untuk melakukan whistle blowing. (Hwang and Staley, 2013).

\section{DAFTAR PUSTAKA}

ACFE. (2006). Diambil dari: http://www.acfe.com, pada tanggal 2 Juni 2014.

Allen Natalie J. \& Meyer John P. (1999). Commitment in the Workplace: Theory, research, and Application. Canada: Canadian Psychological Association

Anayanti Rahmawati. (2010).'Pengaruh Iklim Organisasi, Kepuasan Kompensasi, dan Kecerdasan Emosional terhadap Komitmen Profesi." Tesis tidak diterbitkan. Yogyakarta: Fakultas Ekonomika dan Bisnis Universitas Gadjah Mada.

Dwi Ambarini (2013)."Pelanggaran Etika Bisnis." Jurnal Bisnis dan Ekonomi. (November 2013)

Elias Rafik Z. (2008). “Auditing Students' Professinal Commitment and Anticipatory Socialization and Their Relationship to Whistleblowing." Managerial Auditing Journal. Vol. 23 No. 3.

Hwang Dennis B.K. \& Staley, A. Blair.(2013). "A Comparative Study of the Propensity of WhistleBlowing: Empirical Evidence from China, Taiwan, and the United
States." International Journal of Accounting and Financial Reporting. Vol. 3, No. 2

Imam Ghozali.(2006).Aplikasi Analisis Multivariate dengan Program SPSS.Edisi 4. Semarang: BP-UNDIP

Laksono Trisnantoro. (2013). Ringkasan Hasil Seminar Korupsi di Sektor Kesehatan dan Pencegahannya." Diambil dari http://kebijakankesehatanindonesia.n et, pada tanggal 17 Juni 2014.

Macnab Brent R. \& Worthley Reginald. (2008). "Self-Efficacy as an Intrapersonal Predictor for Internal Whistleblowing: A US and Canada." Journal of Business Ethics. 79.4 (Jun 2008): 407-421.

Management Issues. (2005). Diambil dari: http://www.management-issues.com, pada tanggal 2 Juni 2014

Pusintek. (2004). Diambil dari: http://www.kpmg.com, pada tanggal 2 Juni 2014.

Ratno Purnomo \& SriLestari. (2010). "Pengaruh Kepribadian, Self Efficacy, dan Locus of Control terhadap Persepsi Kinerja Usaha Skala Kecil dan Menengah.”Jurnal Bisnis dan Ekonomi. Hal. 144-160.

Risti Merdikawati.(2012)." Hubungan Komitmen Profesi dan Sosialisasi Antisipatif Mahasiswa Akuntansi dengan Niat Whistle Blowing, Studi Empiris pada Mahasiswa Strata 1 Jurusan Akuntansi di Tiga Universitas Negeri Teratas di Jawa Tengah dan D. I. Yogyakarta." Karya Ilmiah tidak diterbitkan. Semarang: Fakultas Ekonomi Universitas Diponegoro 
Sugiyono. (2010). Metode Penelitian Bisnis.

Bandung: Alfabeta

Theodorus M. Tuanakotta. (2010). Akuntansi Forensik \& Audit Investigatif. Jakarta: Salemba Empat 